\title{
Post-migration Social-Environmental Factors Associated with Mental Health Problems Among Asylum Seekers: A Systematic Review
}

\author{
Sohail Jannesari ${ }^{1} \mathbb{D} \cdot$ Stephani Hatch ${ }^{2,3} \cdot$ Matthew Prina $^{1} \cdot$ Sian Oram ${ }^{1}$
}

Published online: 19 May 2020

(c) The Author(s) 2020

\begin{abstract}
People seeking asylum are at an increased risk of mental disorder compared to refugees and other migrants. This paper aims to understand the impact of postmigration social-environmental factors to help inform efforts to reduce rates of mental disorder. We conducted a systematic review searching 11 databases, as well as 6 government and nongovernment websites. We asked 5 experts for recommendations, and carried out forwards and backwards citation tracking. From 7004 papers 21 were eligible and had the appropriate data. Narrative synthesis was conducted. 24 Social-environmental factors were identified and categorised into 7 themes: working conditions, social networks, economic class, living conditions, healthcare, community and identity, and the immigration system. Evidence suggests that discrimination and post-migration stress are associated with increased rates of mental disorder. The post-migration environment influences the mental health of people seeking asylum. Discrimination and post-migration stress are key factors, warranting further research and public attention.
\end{abstract}

Keywords Refugees $\cdot$ Mental health $\cdot$ Asylum seeker $\cdot$ Discrimination

\section{Introduction}

The UN Refugee Agency [1] estimates there are 25.9 million refugees globally and 3.5 million people seeking asylum. Venezuela, Afghanistan, Syria, Iraq and the Democratic Republic of Congo constitute the top five nationalities for those seeking asylum [1]. In 2018, a decision was made on around a third of asylum applications (1.1 million) with about half of these $(500,100)$ resulting in some form of humanitarian protection [1]. It is clear from these figures

Electronic supplementary material The online version of this article (https://doi.org/10.1007/s10903-020-01025-2) contains supplementary material, which is available to authorized users.

Sohail Jannesari

Sohail.Jannesari@kcl.ac.uk

1 Health Service and Population Research, The Institute of Psychiatry, Psychology and Neuroscience, King's College London, David Goldberg Building, 16 De Crespigny Park, London SE5 8AF, UK

2 Psychological Medicine, The Institute of Psychiatry, Psychology and Neuroscience, King's College London, London, UK

3 ESRC Centre for Society and Mental Health, King's College London, London, UK that the vast majority of applicants spend at least a year in the asylum system. During this time they must navigate an increasingly unwelcome sociopolitical atmosphere. Politicians such as US President Trump have presented people seeking sanctuary as a threat to national security [2]. The marginal EU public sympathy in 2015, when migration flows began to substantially increase, has crystallised into security and financial concerns (e.g. [3].).

Evidence suggests that people seeking asylum are at an increased risk of developing mental disorders compared to refugees and the host population [4]. Potential reasons can be located at different stages of migration: pre-migration, transit and post-migration [5, 6]. Mental health research usually focuses on pre-migration stressors, such as how traumatic experiences in countries of origin affect mental health in host countries [7, 8]. However, post-migration factors mediate the impact of pre-migration stressors on mental health [9-11]. Carswell et al. [12] and Gorst-Unsworth and Goldenberg [13] go further, suggesting that post-migration factors may be more important than pre-migration factors for some forced migrant populations. Gorst-Unsworth and Goldenberg found that only $11 \%$ of Iraqi refugees interviewed in the UK had PTSD though almost $65 \%$ had suffered physical torture in Iraq. Contrastingly, close to $44 \%$ 
had depression and this was primarily associated with a lack of social support in the UK.

In a brief literature review of post-migration risk factors related to asylum policy, Silove et al. [14] argued that low levels of financial support [13], the application process and harsh living conditions [15], as well as loneliness and boredom [16] were associated with as symptoms of depression, PTSD and anxiety. They did not include results from non-Western countries and the review is almost 20 years old. Patel [17] conducted a systematic review of English language papers, finding evidence that detention [18], length of the asylum process [19] and legal status [20] were associated with mental health outcomes such as PTSD symptoms, depression symptoms and psychopathology. Giacco's recent review [21] included studies with both refugees and asylum seekers, suggesting that factors such as a sense of belonging (protective factor) and social isolation (risk factor) are associated with mental disorder. However, the review only considered papers from 2017 onwards and only 3 of the 29 eligible non-review studies included asylum seekers in their sample, with none solely working with asylum seekers.

This review focuses on social-environmental factors, defined by Barnett and Casper [22] as a person's 'immediate physical surroundings, social relationships, and cultural milieus', including 'built infrastructure; labour markets... power relations; government... [and] beliefs about place and community'. Social-environmental factors can change, either through medium-term individual actions or longer-term policy shifts. They are easier to adjust than most sociodemographic factors, character traits, and individual beliefs. Walsh et al. [23] evidence that positive psychology interventions based on character traits such can have poor acceptability and be perceived as belittling. Though skills and competencies such as language ability or vocational qualifications are changeable, they have been excluded to keep the review conceptually coherent and manageable.

An appreciation of social-environmental factors, such as the sociopolitical context in which forced migrants are received, can also lead to more ethical and effective mental health practices and interventions [24]. This is in line with Medical Research Council guidance [25] emphasising the importance of context, a term encompassing social-environmental factors, in the evaluation of complex interventions. Self-Help Plus, for instance, is a mental health intervention developed by the WHO for forced migrants in 'low-resource humanitarian settings' [26]. Accordingly, it was created with a consideration that many forced migrants live in environments with limited access to healthcare, and precarious legal and housing situations. Self-Help Plus also underwent a process of cultural adaptation [27], acknowledging the importance of social norms and beliefs in effective treatment.
This review, therefore, aims to identify, synthesise and appraise the evidence on the association of post-migration social-environmental factors with mental disorder in asylum seekers.

\section{Method}

Systematic review, following the Preferred Reporting Items for Systematic Reviews and Meta-Analyses checklist and (a checklist is provided in Appendix A) registered with Prospero (CRD42017081915).

\section{Search Strategy}

Online searches were in EMBASE, MEDLINE, Social Policy and Practice, PsychINFO, Web of Science, Dissertations and Global Theses, PTSD Publications, Cochrane Library, Cumulative Index to Nursing and Allied Health Literature, Latin American and Caribbean Health Sciences Literature and the Danish Institute Against Torture database. Grey literature databases OpenGrey and Global Health were also searched, as were the websites of several non-profit organisations (see Appendix B). Five experts provided suggestions on studies to include. We conducted forward and backward citation tracking for included studies after full-text screening.

Keyword and medical subject heading searches were conducted from 1 January 1967 to 19 July 2019. January 1967 was chosen as it was the date the UN Protocol Relating to the Status of Refugees was signed. This protocol extended refugee status to those affected by events outside of Europe. The search terms combined terms for mental disorders with terms for asylum seeking statuses [e.g. (exp PTSD/or "post-traumatic stress disorder" or PTSD) and (exp refugees/or asylum\$ or refugee\$ or migrant\$)]. Full search terms are listed in Appendix B.

\section{Inclusion and Exclusion Criteria}

Studies in any language working with asylum seekers over 18 years old were included. Studies with mixed samples where over $75 \%$ were asylum seekers were included. Research including only refugees or internally displaced people was excluded. Studies with populations living in detention, restricted reception centres and refugee camps were excluded. Such extreme living conditions may confound the relationship between asylum status and mental disorder, and are not representative of long-term postmigration living conditions. Studies also had to measure one or more mental disorders using either validated 


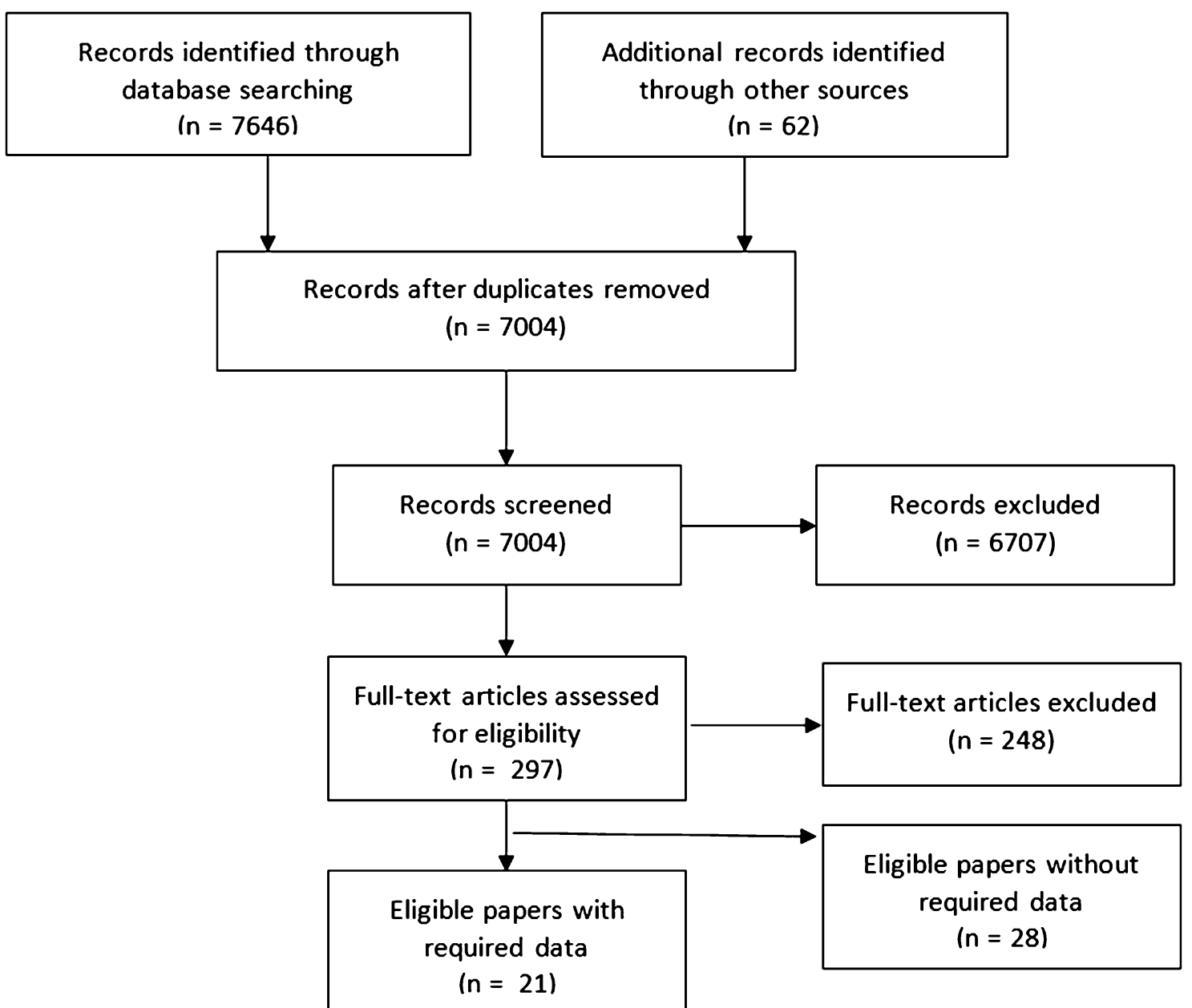

Fig. 1 Study selection

diagnostic or screening tools and to measure one or more social-environmental factor.

\section{Screening and Extraction}

A two-stage screening process was used where title and abstract screening was followed by full-text screening. Two-hundred and fifty studies were independently subject to title and abstract screening by two researchers. There were 23 discrepancies (i.e. $<10 \%$ ) which were discussed and resolved; the primary issue was uncertainty over whether a study included asylum seekers or refugees.

Information on study design, demographics, outcome measures, and results was extracted. Where data was missing or not disaggregated, authors were contacted. The Newcastle-Ottawa Assessment Scale [28] assessed quality for case-control and cohort studies, and an adapted version [29] was used for cross-sectional studies. We adapted the scale for use in the forced migration context (see Appendix C).

\section{Analysis}

Analysis included description of study and population characteristics, calculation of odds ratios and $95 \%$ confidence intervals (if raw numbers were available). Narrative synthesis first sorted study variables into 24 common factors. Factors were then placed into conceptually coherent themes based on the International Organisation for Migration's [30] social determinants of migrant health, an adaption of a World Health Organisation 2008 model [31]. Synthesis then followed the stages described by Popay et al. [32]: 'developing a preliminary synthesis'-we organised the results 
in tables to identify patterns, "exploring relationships in the data' - we considered the role of study heterogeneity in emerging patterns, and 'assessing the robustness of the synthesis product' - we evaluated the strength of evidence for each pattern. Synthesis was conducted for factors with six or more separate studies, and for studies reporting overall post-migration stress.

\section{Results}

We identified 7004 unique references (Fig. 1). After title and abstract screening, 297 papers remained for full-text screening, 49 of which were eligible (Appendix D). Of these, the required data could only be extracted from 11. After data requests, a further 10 studies were included to make 21 total.

The number of adult asylum seekers in studies totalled 2402 (Table 1), with 1679 men and 856 women, and a median age of $34(n=15)$. Sudan and Iraq were the most common nationalities (Fig. 2). Research primarily occurred in high-income countries with majority white populations, with the USA (19\% of studies) and Australia (19\%) most frequent. $71 \%$ of studies were cross-sectional (29\% prospective cohort) and 59\% used convenience sampling. PTSD was the most commonly assessed outcome ( $90 \%$ of studies) followed by depression (86\%) and anxiety (48\%). Median prevalence for depression $(\mathrm{n}=9)$ was $68 \%$ (IQR 50\%, 85\%), for anxiety $(\mathrm{n}=6) 48 \%$ (IQR 46\%, 61\%), and PTSD $(\mathrm{n}=10)$ ) 39\% (IQR $36 \%, 51 \%)$.

Studies measured 24 social-environmental factors which we grouped into seven domains: working conditions, social networks, economic class, living conditions, healthcare, community and identity, and the immigration system (Fig. 3). The most frequently used risk factor tool was the Post-Migration Living Difficulties Questionnaire (PMLD, 10 studies), developed by Silove et al. [15].

Immigration system was the most examined category (18 studies), including the largest variety of factor types (5). Social networks received the least attention (8 studies) and had the fewest factor types (2). Although all studies focussed on mental health, access to counselling was only reported by two studies $[15,41]$. Items in this theme were limited, seldom considering the impact of culture and language on healthcare quality.

Factors were typically broadly defined. In examining the asylum interview, several papers [15, 20, 49] asked whether 'interviews by immigration officials' were a source of stress. However, this could include immigration officers at the border, interviewers in an asylum interview or tribunal judges in court. Schock et al. [45] provided the exception, focussing on the asylum interview, breaking it down different potential sources of stress: 'perceived justice of the hearing', 'testimony stress' and 'delay stress'. Similarly, some factors combined potentially separate risk factors into one. Loneliness and boredom was created as a factor group because studies often grouped them [20, 35, 41].

Three studies [40, 44, 51] provided strong evidence that discrimination is associated with higher rates of mental disorder and four [15, 20, 35, 41] found weak evidence of an association. The former set had larger samples and used several questions to arrive at a discrimination score, contrasting with the single item discrimination statement used in the other studies.

In their study with 294 Iraqi asylum seekers, Laban et al. [40] found a strong association between increased levels of discrimination and increased depression, anxiety and somatoform disorder ( $\mathrm{p}=<0.01$ for all results). In their multivariate analysis, Wong et al. [51] found a small association between everyday discrimination and depression $(\mathrm{OR}=1.2$, 95\% CI 1.10-1.24) among a sample of 374 African asylum seekers in Hong Kong. Ryan et al. [44] worked with 162 people from 38 different countries, finding that discrimination was positively associated with distress in their multiple regression $(\beta=0.29, \mathrm{p}<0.001)$.

The four other studies generally found no association between discrimination and mental disorders in their analyses. Silove et al. [15] did, however, find an association between discrimination and increased PTSD (95\% CI 4.52-22.50), Morgan et al. [41] with decreased anxiety $(\mathrm{r}=-0.36, \mathrm{p}=0.02)$, Nickerson et al. [20] with increased depression (OR $=5,95 \%$ CI 4.54-49.44) and Hecker et al. [35] with complex PTSD (OR=3.6, 95\% CI 3.16-17.6). Confidence intervals in all studies were broad due to small sample sizes, while results were not part of a multivariate model accounting for confounders.

Two studies [37, 43] found evidence for an association between unemployment and mental disorder, with five [33, $34,39,41,47]$ finding no evidence. In their study with 90 asylum seekers in Israel, Nakash et al. [43] found that unemployment was associated with higher rates of depression ( $\mathrm{OR}=2.1,95 \%$ CI 1.04-5.09). Hocking et al. [37] also found an association between depression and unemployment $(\mathrm{OR}=2.16,95 \%$ CI $1.02-4.56)$ in their study with 115 people seeking asylum in Australia.

Morgan et al. [41] found no evidence of a relationship between 'not being able to find work', a proxy for unemployment, and anxiety $(\mathrm{r}=0.21, \mathrm{p}=0.182)$, depression $(\mathrm{r}=0.035, \mathrm{p}=0.826)$ or PTSD $(\mathrm{r}=-0.106, \mathrm{p}=0.504)$. Eisen [34] found no evidence of an association between unemployment and PTSD $(\beta=-0.029, \mathrm{p}=0.766)$ or depression $(\beta=-0.036 ; p=0.712)$, a pattern repeated for Sohn [47] with depression $(\mathrm{OR}=1.19,95 \% \mathrm{CI} 0.21-6.61)$ and PTSD (OR $=1.821,95 \%$ CI 0.34-9.91), Kashyap et al. [39] for depression $(\beta=-0.1 ; p=0.28)$ and PTSD $(\beta=-0.06$; $\mathrm{p}=0.51)$, and Boersma [33] for depression $(\mathrm{r}=-0.033$, $\mathrm{p}=3.61)$ and somatization $(\mathrm{r}=-0.04, \mathrm{p}=-0.336)$. Results 
Table 1 Study characteristics [15, 20, 33-51]

\begin{tabular}{|c|c|c|c|c|c|c|c|c|c|c|}
\hline \multirow[t]{2}{*}{ Lead author } & \multirow[t]{2}{*}{ Year } & \multirow[t]{2}{*}{$\mathrm{N}$} & \multicolumn{2}{|c|}{ Gender } & \multirow[t]{2}{*}{ Age $(\bar{x})$} & \multirow[t]{2}{*}{ Countries of origin } & \multirow[t]{2}{*}{ Host } & \multirow[t]{2}{*}{ Design } & \multirow[t]{2}{*}{ Outcomes } & \multirow[t]{2}{*}{ Tool } \\
\hline & & & M & $\mathrm{F}$ & & & & & & \\
\hline Boersma & 2005 & 117 & 70 & 47 & 41.6 & Nigeria, Lebanon & USA & $\mathrm{CS}$ & $\begin{array}{l}\text { Depression } \\
\text { Somatoform }\end{array}$ & $\begin{array}{l}\text { HSCL-25 } \\
\text { SCL-90 }\end{array}$ \\
\hline Eisen & 2016 & 78 & 33 & 45 & 34.1 & Ethiopia, Cameroon & USA & Prospect. cohort & $\begin{array}{l}\text { Depression } \\
\text { PTSD }\end{array}$ & $\begin{array}{l}\text { HSCL-25 } \\
\text { HTQ-30 }\end{array}$ \\
\hline Hecker & 2018 & 61 & 56 & 5 & 28.64 & Afghanistan, Syria & Switzerland & CS & $\begin{array}{l}\text { Depression } \\
\text { PTSD, CPTSD }\end{array}$ & $\begin{array}{l}\text { PHQ-9 } \\
\text { ICD-11 }\end{array}$ \\
\hline Heeren & 2012 & 86 & 60 & 16 & 29.8 & African and the Middle East ${ }^{\mathrm{a}}$ & Switzerland & $\mathrm{CS}$ & $\begin{array}{l}\text { Depression } \\
\text { Anxiety, PTSD }\end{array}$ & MINI \\
\hline Hocking & 2015 & 115 & 103 & 102 & 35.2 & Sri Lanka & Australia & $\mathrm{CS}$ & $\begin{array}{l}\text { Depression } \\
\text { Anxiety } \\
\text { PTSD }\end{array}$ & $\begin{array}{l}\text { HCSL-25 } \\
\text { HSCL-25 } \\
\text { HTQ }\end{array}$ \\
\hline Kaltenbach & 2018 & 15 & 4 & 11 & 35.87 & Syria, Iraq, Iran, & Germany & Prospect. cohort & $\begin{array}{l}\text { Depression } \\
\text { PTSD }\end{array}$ & $\begin{array}{l}\text { PHQ-9 } \\
\text { HTQ }\end{array}$ \\
\hline Kashyap & 2019 & 122 & 78 & 44 & 39.07 & Ethnicities recorded & Australia & Prospect. cohort & $\begin{array}{l}\text { Depression } \\
\text { PTSD }\end{array}$ & $\begin{array}{l}\text { PHQ-9 } \\
\text { PCL }\end{array}$ \\
\hline Laban & 2005 & 294 & 190 & 104 & & Iraq & Netherlands & CS (Control) & $\begin{array}{l}\text { Depression } \\
\text { Anxiety, PTSD, } \\
\text { Somatoform }\end{array}$ & CIDI \\
\hline Morgan & 2017 & 42 & & & & $\begin{array}{l}\text { African countries inc. Zim- } \\
\text { babwe, DRC/Congo }\end{array}$ & UK & $\mathrm{CS}$ & $\begin{array}{l}\text { Anxiety } \\
\text { PTSD }\end{array}$ & $\begin{array}{l}\text { HSCL-25 } \\
\text { HTQ }\end{array}$ \\
\hline Müller & 2018 & 78 & 33 & 45 & 38.2 & Turkey & Germany & CS & $\begin{array}{l}\text { Depression } \\
\text { Anxiety, PTSD } \\
\text { Schizophrenia }\end{array}$ & ICD-10 \\
\hline Nakash & 2017 & 90 & 90 & 0 & 30.7 & Sudan, Eritrean & Israel & $\mathrm{CS}$ & $\begin{array}{l}\text { Depression } \\
\text { Anxiety } \\
\text { PTSD }\end{array}$ & $\begin{array}{l}\text { HSCL-25 } \\
\text { HSCL-25 } \\
\text { PCL }\end{array}$ \\
\hline Nickerson & 2015 & 30 & 23 & 7 & & Turkey & Switzerland & $\mathrm{CS}$ & $\begin{array}{l}\text { Depression } \\
\text { PTSD }\end{array}$ & $\begin{array}{l}\text { HSCL-25 } \\
\text { PDS }\end{array}$ \\
\hline Ryan & 2008 & 162 & 202 & 152 & 32.5 & Nigeria & Ireland & Prospect. cohort & Distress & SCL-90R \\
\hline Schock & 2015 & 50 & 30 & 20 & 32.1 & Iran, Turkey, Balkans & Germany & Prospect. cohort & $\begin{array}{l}\text { Depression } \\
\text { Anxiety } \\
\text { PTSD }\end{array}$ & $\begin{array}{l}\text { HCSL-25 } \\
\text { HCSL-25 } \\
\text { PDS }\end{array}$ \\
\hline Silove & 1997 & 40 & 21 & 19 & 35 & Data not available & Australia & $\mathrm{CS}$ & $\begin{array}{l}\text { Depression } \\
\text { Anxiety } \\
\text { PTSD }\end{array}$ & $\begin{array}{l}\text { HCSL-25 } \\
\text { HCSL-25 } \\
\text { CIDI }\end{array}$ \\
\hline Slonim-Nevo & 2015 & 340 & 276 & 64 & 30.6 & Sudanese & Israel & $\mathrm{CS}$ & PTSD & PCL \\
\hline Sohn & 2019 & 129 & 93 & 36 & & Nigeria, Ethiopia & South Korea & $\mathrm{CS}$ & $\begin{array}{l}\text { Depression } \\
\text { PTSD }\end{array}$ & $\begin{array}{l}\text { PHQ-9 } \\
\text { IES-R }\end{array}$ \\
\hline Song & 2010 & 44 & 24 & 20 & 36 & Iran, Eritrea, Iraq ${ }^{a}$ & USA & $\mathrm{CS}$ & $\begin{array}{l}\text { Depression } \\
\text { Anxiety } \\
\text { PTSD }\end{array}$ & $\begin{array}{l}\text { HSCL-25 } \\
\text { HSCL-25 } \\
\text { PCL }\end{array}$ \\
\hline Steel & 1999 & 296 & 135 & 64 & 43.7 & Sri Lanka & Australia & CS & PTSD & HTQ \\
\hline Whitsett & 2017 & 105 & 41 & 64 & 34.76 & Ethiopia, Cameroon & USA & $\mathrm{CS}$ & $\begin{array}{l}\text { Depression } \\
\text { Anxiety } \\
\text { PTSD }\end{array}$ & $\begin{array}{l}\text { HCSL-25 } \\
\text { HSCL-25 } \\
\text { HTQ }\end{array}$ \\
\hline Wong & 2016 & 374 & 292 & 82 & 31.52 & Not available & China-HK & $\mathrm{CS}$ & PTSD & PHQ-2 \\
\hline
\end{tabular}

${ }^{\mathrm{a}}$ Only main regions and countries displayed in table 


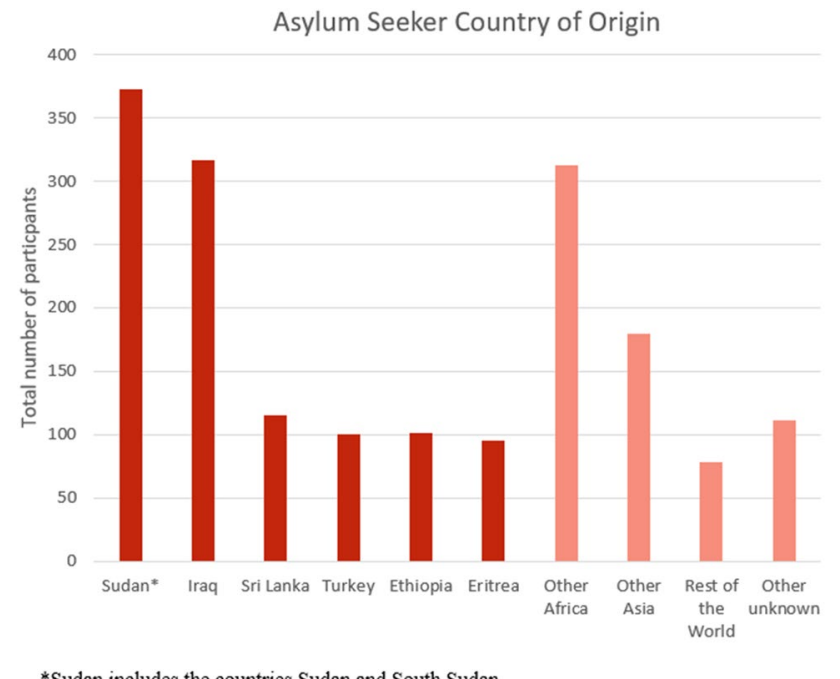

*Sudan includes the countries Sudan and South Sudan

Fig. 2 Top six asylum seeker countries of origin ( $\mathrm{n}=21$ studies)

could be confounded because participants working without permission do not want to reveal this to researchers. Only Eisen [34] considered work authorisation, using an employment rating scale developed by the Advocates for Survivors of Torture and Trauma charity (cited in Eisen, p. 41).

Five studies [20, 40, 42, 44, 49] reported a score for general post-migration living difficulties derived from some of the factors in Fig. 3. Four of these studies reported that post-migration problems are associated with increased odds of mental disorder-all aside from Muller et al. [42]. The majority (4 of 5 studies) used a measure derived from the 23-item PMLD developed by Silove et al. [15]. Both Ryan et al. [44] and Nickerson et al. [20] used a condensed form of the checklist tailored to their study context (17 and 13 items respectively).

Nickerson et al. [20] found that increases in migration living difficulties were associated with higher rates of depression (total effects ${ }^{1}=0.06, p=<0.001$ ) and PTSD (total effects $=0.07, p=<0.001$ ). Ryan et al. [44] similarly found that higher overall scores on their post-migration checklist was related to higher rates of distress $(\beta=0.44$, $\mathrm{p}=<0.000$ ). Though Muller et al. [42] did not conduct any statistical comparison, there appeared to be no difference in the number of migration-related stressors between Turkish people seeking asylum in Germany with PTSD and those without (5.25 stressors against 6 , in a sample of 16 and 13 respectively).

\footnotetext{
1 'Total effects are the sum of direct and indirect effects that connect a predictor to an outcome' [61].
}

Ryan et al.'s [44] principal component analysis (PCA) identified three groups of post-migration living difficulties; higher scores in each were associated with increased rates of distress: basic living difficulties $(r=0.56 \mathrm{p}=0.000)$, asylum stress $(\rho=0.27 \mathrm{p}=0.001)$ and family separation $(r=0.02$, $\mathrm{p}=0.005)$. Laban et al.'s [40] factor analysis created the similar categories: family issues, the asylum procedure, socioeconomic living conditions and discrimination, and socioreligious living conditions. Increases in category scores associated with increases anxiety, depression and somatoform disorder ( $p<0.05$ for all categories). Steel et al.'s [49] PCA produced the themes: residency determination; threat to family; health care, welfare and asylum; adaptation difficulties and loss of culture and support. Results from the latter three were reported and higher scores were positively associated with posttraumatic symptoms $(\beta=0.24,0.33$ and 0.27 respectively).

The categories developed through PCA and factor analysis were not always conceptually coherent. In the paper from Steel et al. [49] 'healthcare, welfare and asylum' included elements as disparate as 'poor access to emergency medical care', 'delays in processing your application' and 'little help with welfare from charities'. In Ryan et al.'s [44] paper 'basic living difficulties' encompassed 'racism and discrimination', 'financial concerns' and 'dietary concerns', and there was overlap with the 'asylum stress' category which included 'work permission'.

\section{Discussion}

Our review identified 24 social-environmental risk factors for asylum seeker mental health from 21 papers and categorised them into 7 domains: working conditions, social networks, economic class, living conditions, healthcare, community and identity, and the immigration system. Most risk factors were examined by only a few studies, but synthesis of findings was possible for discrimination (community and identity), unemployment (working conditions), and post-migration stress (encompassing multiple domains). Strengths of the review included its comprehensive approach and robust search strategy. However, despite requests to corresponding authors for assistance, data could not be extracted for a large proportion of eligible papers. Consequently, work from research hubs in Australia and the Netherlands was excluded, and significant nationality groups such as Syrians and Afghans underrepresented.

Findings suggested a link between discrimination and mental disorder, though study setting and measurement approaches were heterogeneous. The larger studies, using more nuanced scales to investigate different facets of discrimination, more consistently reported an association 


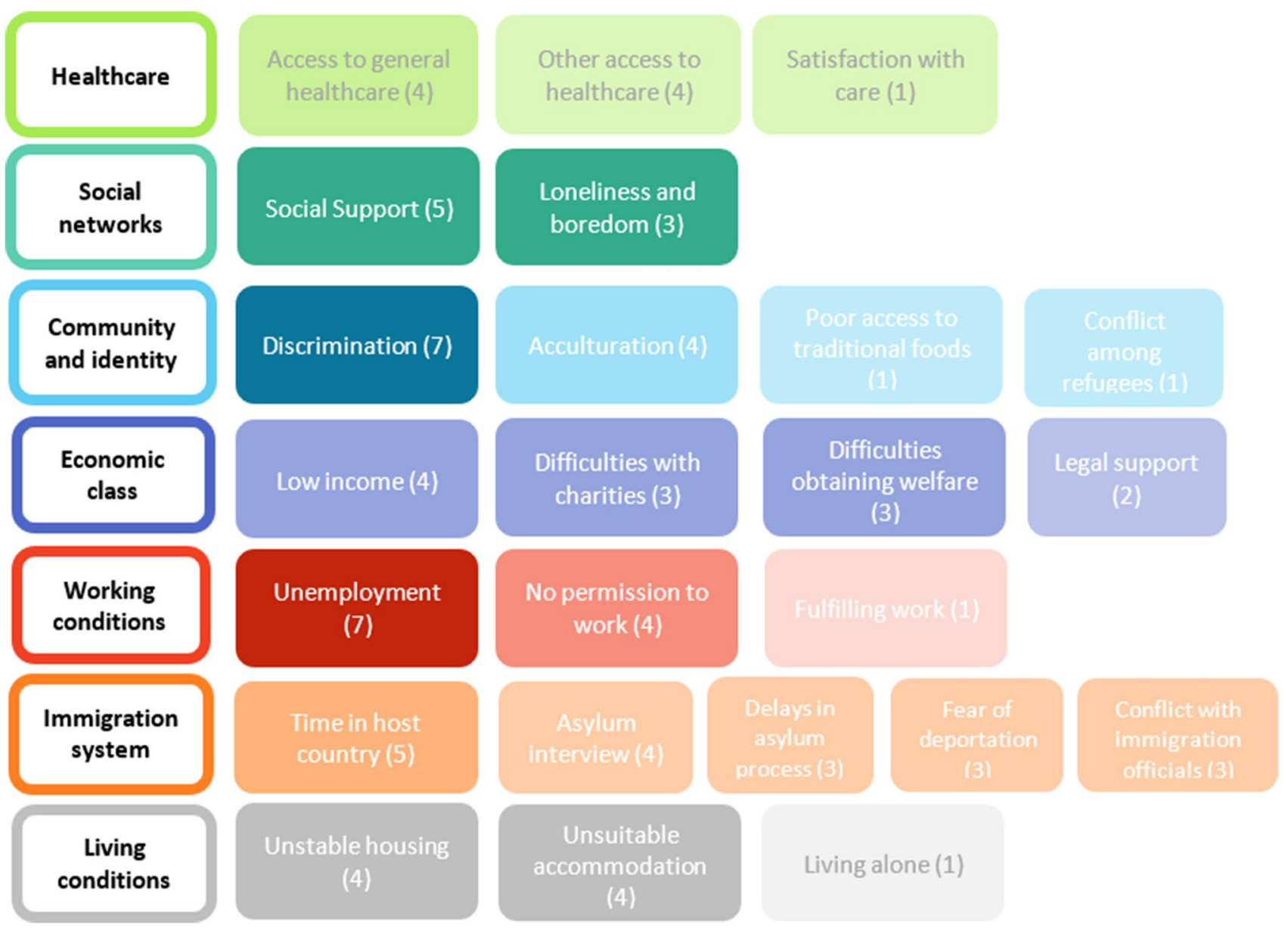

Fig. 3 A map of social-environmental factors in included studies. Block shaded according to the number of studies; darker shading indicates more studies (number of studies in brackets)

between discrimination and mental disorder. In comparison, the smaller studies used single-item measures. The seven studies examining this relationship were conducted in different countries and, largely, with different nationalities. Experience of discrimination may vary by setting and by asylum seeker nationality and ethnicity [52], it is not clear whether its impact on mental disorder also varies. However, our findings reflect the broader literature on mental health and discrimination, including from large meta-analyses $[53,54]$ as well as findings from studies conducted with refugees [55].

In contrast with the wider mental health literature [17], findings from the seven studies assessing unemployment suggested only a weak positive association with mental disorder. However, the majority of studies investigating this association did not consider a potential confounder: working without authorisation, which may be common but not readily disclosed [56]. Those working without permission may be subject to additional stressors such as forced labour, unpaid wages and a lack of institutional recourse [57]. Future studies could use scales that incorporate unauthorised working, such as the employment scale used by Eisen et al. [34].

There was good evidence suggesting that post-migration stress as a broad category is associated with higher rates of mental disorder, with four of the five studies investigating this finding evidence for an association. Our work reinforces recent appeals from academics to consider post-migration factors in greater depth [58]. Further research could explore domains within post-migration stress, such as living conditions and healthcare in more detail. Factors relating to the asylum process were key components of all of general post-migration stress score measures. As a category readily changeable through government policy, this could form a focus for future research and advocacy. The broad crosscutting categories around post-migration developed through PCA were not always conceptually coherent. The categories developed in this review could provide a basis for grouping factors in future studies.

The included studies examined a broad range of risk factors, exemplified by the reliance on the Post-Migration 
Living Difficulties checklist which uses single item questions for complex issues such as discrimination. Even in the domain with the greatest number of individual risk factors (the immigration system) risk factors were wide-ranging and ill-defined. Schock et al. [45] provide a useful model for future research by focussing on the substantive asylum interview and breaking down different potential sources of stress. Similarly, measurement of access to healthcare could have been improved by recognising the impact of culture and language on the quality of healthcare. Nellums et al. [59] have found, for example, that healthcare access for people seeking asylum was inhibited by the lack of translators or the use of inappropriate translators (friends and family, or male interpreters for women's sexual health services).

Understanding of how post-migration environmental factors impact the mental health of people seeking asylum would be deepened if studies asked separate questions about related but distinct concepts. For example, while Morgan et al. [41] asked participants about 'mistakes and delays in the application process', Jannesari et al. [60] have reported that people seeking asylum have different experiences and reactions to delays as opposed to mistakes (particularly trivial ones with significant consequences). Similarly, while many studies combined loneliness and boredom, Ryan et al.'s [44] Post-Arrival Concern Checklist assessed them as separate concepts.

Our comprehensive search strategy, accepting papers from all languages, looking at any mental disorder and social-environmental risk factor, is a key strength of our review. As is the large range of databases and sources used to identify papers. A major limitation was the number of eligible papers for which data could not be extracted ( 28 of 49 ).

\section{Conclusion}

It has long been established that people seeking asylum have a high prevalence of mental disorder compared to host and other migrant populations. This review begins to address why this might be. Findings suggest both discrimination and general post-migration stress are linked to an increased risk of mental disorder, with a possible protective role for employment. With anti-migrant rhetoric increasing in many places worldwide, discrimination and restrictions on the freedoms and entitlements of people seeking asylum could increase, with potentially negative consequences for mental health.

\section{New Contribution to the Literature}

This review considers why the prevalence of mental disorder is high among people seeking asylum compared to other migrants and refugees. It investigates the role of social-environmental risk factors in the post-migration period. No limits were placed on language, country, or type of mental disorder. We synthesise evidence on a vast array of risk factors (often using data initially unreported in papers) into seven risk domains: working conditions, social networks, economic class, living conditions, healthcare, community and identity, and the immigration system. Findings suggest that discrimination and post-migration stress are associated with an increased risk of mental disorder in people seeking asylum.

With anti-migrant rhetoric increasing in many places worldwide, discrimination against people seeking asylum could increase, with potentially negative consequences for mental health. The reduction of discrimination should be considered when forming asylum policy. Several risk domains, including living conditions and healthcare, remain under-researched and should be explored in future work. We also recommend the use of more nuanced measures of discrimination, employment and other risk factors to arrive at more meaningful findings.

Funding The Economics and Social Research Council funded Sohail's $\mathrm{PhD}$. This work forms part of his $\mathrm{PhD}$.

\section{Compliance with Ethical Standards}

Conflict of interest There are no conflicts of interest.

Ethics Approval Approval for this research was obtained from King's College London Psychiatry, Nursing and Midwifery Research Ethics Subcommittee.

Open Access This article is licensed under a Creative Commons Attribution 4.0 International License, which permits use, sharing, adaptation, distribution and reproduction in any medium or format, as long as you give appropriate credit to the original author(s) and the source, provide a link to the Creative Commons licence, and indicate if changes were made. The images or other third party material in this article are included in the article's Creative Commons licence, unless indicated otherwise in a credit line to the material. If material is not included in the article's Creative Commons licence and your intended use is not permitted by statutory regulation or exceeds the permitted use, you will need to obtain permission directly from the copyright holder. To view a copy of this licence, visit http://creativecommons.org/licenses/by/4.0/.

\section{References}

1. United Nations Refugee Agency. Global trends, forced displacement in 2018. 2019. https://www.unhcr.org/statistics/unhcrstats 15d08d7ee7/unhcr-global-trends-2018.html. Accessed 1 Mar 2020. 
2. Scribner T. You are not welcome here anymore: restoring support for refugee resettlement in the age of Trump. J Migr Hum Secur. 2017;5(2):263-84.

3. Greussing E, Boomgaarden HG. Shifting the refugee narrative? An automated frame analysis of Europe's 2015 refugee crisis. J Ethn Migr Stud. 2017;43(11):1749-74.

4. Ryan DA, Kelly FE, Kelly BD. Mental health among persons awaiting an asylum outcome in Western countries. Int J Ment Health. 2014;38(3):89-111.

5. Wessels WK. The refugee experience: involving pre-migration, in transit, and post migration issues in social services. Thesis, St Catherine University, 2014.

6. Zimmerman C, Kiss L, Hossain M. Migration and health: a framework for 21st century. Public Libr Sci Med. 2011;8(5):e.1001034.

7. Bhui K, Abdi A, Abdi M, Pereira S, Dualeh M, Robertson D, Sathyamoorthy G, Ismail $\mathrm{H}$. Traumatic events, migration characteristics and psychiatric symptoms among Somali refugees. Soc Psychiatry Psychiatr Epidemiol. 2003;38:35-433.

8. Lindencrona F, Solvig E, Hauff E. Mental health of recently resettled refugees from the Middle East in Sweden: the impact of preresettlement trauma, resettlement stress and capacity to handle stress. Soc Psychiatry Psychiatr Epidemiol. 2008;43(2):121-31.

9. Khawaja N, White K, Schweitzer R, Greenslade J. Difficulties and coping strategies of Sudanese refugees: a qualitative approach. Transcult Psychiatry. 2008;45(3):489-512.

10. Miller KE, Rasmussen A. Social Science and Medicine War exposure, daily stressors, and mental health in conflict and post-conflict settings. Soc Sci Med. 2010;70(1):7-16.

11. Watters C. Emerging paradigms in the mental health care of refugees. Soc Sci Med. 2001;52(11):1709-18.

12. Carswell K, Blackburn P, Barker C. The relationship between trauma, post-migration problems and the psychological wellbeing of refugees and asylum seekers. Int J Soc Psychiatry. 2009;57(2):107-19.

13. Gorst-Unsworth C, Goldenberg E. Psychological sequelae of torture and organised violence suffered by refugees from Iraq. Br J Psychiatry. 1998;172:90-4.

14. Silove D. Policies of deterrence and the mental health of asylum seekers. J Am Med Assoc. 2000;284(5):604-11.

15. Silove D, Sinnerbrink I, Field A, Steel Z. Anxiety, depression and PTSD in asylum-seekers: associations with pre-migration trauma and post-migration stressors versus special characteristics. Br J Psychiatry. 1997;170(April):351-7.

16. Steel Z, Mohan P. Trauma exposure, postmigration stressors, and symptoms of anxiety, depression and post-traumatic stress in Tamil. Acta Psychiatr Scand. 1998;97(3):175-81.

17. Patel S. Health and Asylum: what is the influence of asylumprocesses on asylum-seekers' health? Thesis, London School of Hygiene and Tropical Medicine, London, 2011.

18. Robjant K, Robbins I, Senior V. Psychological distress amongst immigration detainees: a cross-sectional questionnaire study. J Br Psychol Soc. 2009;48:275-86.

19. Nielsen SS, Norredam M, Christiansen KL, Obel C, Hilden J, Krasnik A. Mental health among children seeking asylum in Denmark-the effect of length of stay and number of relocations: a cross-sectional stud. BioMed Cent Public Health. 2008. https:// doi.org/10.1186/1471-2458-8-293.

20. Nickerson A, Schnyder U, Bryant RA, Schick M, Mueller J, Morina N. Moral injury in traumatized refugees. Psychother Psychosom. 2015;84(2):122-3.

21. Giacco D, Laxham N, Priebe S. Prevalence of and risk factors for mental disorders in refugees. Semin Cell Dev Biol. 2018;77:144-52.

22. Barnett E, Casper M. A definition of "Social Environment". Am J Public Health. 2001;91(3):465. https://doi.org/10.2105/ ajph.91.3.465a.
23. Walsh S, Kaselionyte J, Taylor SJC, Priebe S. What might affect acceptability of online positive psychology interventions for depression: a qualitative study on patient expectations. BMC Psychiatry. 2018;240:1-12.

24. Watters C. Emerging paradigms in the mental health care of refugees. Soc Sci Med. 2001;52:1709-18.

25. Moore G, Audrey S, Baker M, Bond L, Bonell C, et al. Process evaluation of complex interventions, UK Medical Research Council (MRC) guidance. 2015. https://mrc.ukri.org/documents/pdf/ mrc-phsrn-process-evaluation-guidance-final/. Accessed 1 Mar 2020.

26. Brunie A, Chaib F. Guided self-help intervention reduces refugees' psychological distress and improves wellbeing in humanitarian crises. 2020. https://www.who.int/news-room/detail/2301-2020-guided-self-help-intervention-reduces-refugees-psych ological-distress-and-improves-wellbeing-in-humanitarian-crises. Accessed 1 Mar 2020.

27. Au T, Carswell K. Report on adaptation of SH+. 2018; unpublished.

28. Wells GA, Shea B, O'Connell D, Peterson J, Welch V, Losos M. The Newcastle-Ottawa Scale (NOS) for assessing the quality of nonrandomised studies in meta-analyses. 2003. https://www.ohri. ca/programs/clinical_epidemiology/oxford.asp. Accessed 1 Oct 2019.

29. Herzog R, Álvarez-Pasquin MJ, Díaz C, Luis J, Barrio D, Estrada JM, Gil A. Are healthcare workers' intentions to vaccinate related to their knowledge, beliefs and attitudes? BioMed Cent Public Health. 2013;13(154):1-17.

30. International Organisation for Migration. Migration and the social determinants of health. 2017. https://migrationdataportal.org/ infographic/migration-and-social-determinants-health. Accessed 1 Oct 2019.

31. World Health Organisation. Closing the gap in a generation. 2008. https://www.who.int/social_determinants/thecommission/final report/en/. Accessed 1 Oct 2019.

32. Popay J, Roberts H, Sowden A, Petticrew M, Arai L, et al. Guidance on the conduct of narrative synthesis in systematic reviews. 2006. https://citeseerx.ist.psu.edu/viewdoc/download?doi=10.1. 1.178.3100\&rep=rep1\&type $=$ pdf. Accessed 1 Oct 2019.

33. Boersma R. Depression and somatization in community based asylum-seekers Thesis, Boston College, Boston, 2005.

34. Eisen E. The impact of post-migration factors on PTSD and depressive symptoms among asylum seekers in the United States. Thesis, The George Washington University, Washington, DC, 2016.

35. Hecker T, Huber S, Maier T, Maercker A. differential associations among PTSD and complex PTSD symptoms and traumatic experiences and postmigration difficulties. J Trauma Stress. 2018;31:795-804.

36. Heeren M, Mueller J, Ehlert U, Schnyder U, Copiery N, Maier T. Mental health of asylum seekers: a cross-sectional study of psychiatric disorders. BioMed Cent Psychiatry. 2012;12(114):2-8.

37. Hocking DC, Kennedy GA, Sundram S. Mental disorders in asylum seekers: the role of the Refugee Determination Process and Employment. J Nerv Ment Dis. 2016;203(1):28-322.

38. Kaltenbach E, Schauer M, Hermenau K, Elbert T. Course of mental health in refugees - a One Year Panel Survey. Front Psychiatry. 2018;9(August):1-12.

39. Kashyap S, Page AC, Joscelyne A. Post-migration treatment targets associated with reductions in depression and PTSD among survivors of torture seeking asylum in the USA. Psychiatry Res. 2019;271:565-72.

40. Laban CJ, Gernaat H, Komproe IH. Postmigration living problems and common psychiatric disorders in Iraqi asylum seekers in the Netherlands. J Nerv Ment Dis. 2006;193(12):825-32. 
41. Morgan G, Melluish S, Welham A. Exploring the relationship between postmigratory stressors and mental health for asylum seekers and refused asylum seekers in the UK. Transcult Psychiatry. 2017;54(5-6):653-74.

42. Müller MJ, Zink S, Koch E. The negative impact of an uncertain residence status: analysis of migration-related stressors in outpatients with Turkish migration background. J Immigr Minor Health. 2018;20(2):317-26.

43. Nakash O, Nagar M, Shoshani A, Lurie I. The association between perceived social support and posttraumatic stress symptoms among Eritrean and Sudanese male asylum seekers in Israel. Int J Cult Ment Health. 2017;10(3):261-75.

44. Ryan DA, Benson A, Dooley BA. Psychological distress and the asylum process a longitudinal study of forced migrants in Ireland. J Nerv Ment Dis. 2008;196(1):37-45.

45. Schock K, Rosner R, Knaevelsrud C. Impact of asylum interviews on the mental health of traumatized asylum seekers. Eur J Psychotraumatol. 2015;6(1):262-86.

46. Slonim-Nevo V, Regev S. Risk factors associated with culture shock among asylum seekers from Darfur. J Refug Stud. 2015;29(1):117-38.

47. Sohn JH, Lim J, Lee JS, Kim K, Lim S, Byeon N, Kim DW, Kim KH, Kim MS, Cho SJ, Seo HY, Park JE, Kwon YJ, Kwon JS, Ahn C. Prevalence of possible depression and post-traumatic stress disorder among community dwelling adult refugees and refugee applicants in South Korea. J Korean Med Sci. 2019;34(11):1-12.

48. Song SJ, Kaplan C, Tol WA. Psychological distress in torture survivors: pre- and post-migration risk factors in a US sample. Soc Psychiatry Psychiatr Epidemiol. 2015;50:549-60.

49. Steel Z, Mohan P. Trauma exposure, postmigration stressors, and symptoms of anxiety, depression and post-traumatic stress in Tamil. Acta Psychiatr Scand. 1998;97:175-81.

50. Whitsett D, Sherman MF. Do resettlement variables predict psychiatric treatment outcomes in a sample of asylum-seeking survivors of torture ? Int J Soc Psychiatry. 2017;63:647-85.

51. Wong W, Cheung S, Yin H, Miu H, Chen J, Loper K, Holroyd E. Mental health of African asylum-seekers and refugees in Hong Kong: using the social determinants of health framework. BioMed Cent Public Health. 2017;17(153):1-9.
52. Jasperse M, Ward C, Jose PE. Identity, perceived religious discrimination, and psychological well-being in Muslim immigrant women. Appl Psychol Int Rev. 2011;61(2):1-22.

53. Pascoe EA, Richman LS. Perceived discrimination and health, a meta-analytic review. Psychol Bull. 2009;135(4):531-54.

54. Schmitt MT, Postmes T, Garcia A. The consequences of perceived discrimination for psychological well-being: a meta-analytic review. Psychol Bull. 2014;140(4):921-48.

55. Noh S, Beiser M, Kaspar FH, Hou F, Rummens J. Perceived racial discrimination, depression, and coping: a study of Southeast Asian refugees in Canada. J Health Soc Behav. 2019;40(3):193-207.

56. Bloch A, Sigona N, Zetter R. Migration routes and strategies of young undocumented migrants in England: a qualitative perspective. Ethn Racial Stud. 2011;34(8):1286-302.

57. Lewis, Dwyer P, Hodkinson S, Waite L. Precarious lives: experiences of forced labour among refugees and asylum seekers in England (report). University of Leeds; 2013.

58. Hynie $M$. The social determinants of refugee mental health in the post-migration context: a critical review. Can J Psychiatry. 2018;63(5):297-303.

59. Nellums L, Rustage K, Hargreaves S, Friedland J, Miller A, Hiam L. Access to healthcare for people seeking and refused asylum in Great Britain (report). Equality and Human Rights Commission; 2018.

60. Jannesari S, Molyneaux E, Lawrence V. What affects the mental health of people seeking asylum in the UK? A narrative analysis of migration stories. Qual Res Psychol. 2019. https://doi. org/10.1080/14780887.2019.1581311.

61. Cudeck R, du Toit S. General structural equation models. In: Millsap R, Maydeu-Olivares A, editors. The SAGE Handbook of Qualitative Methods in Psychology. London: SAGE Publications Ltd.; 2009. p. 515-39.

Publisher's Note Springer Nature remains neutral with regard to jurisdictional claims in published maps and institutional affiliations. 